\title{
Video Game Play May Attenuate Cortisol Response to Psychosocial Stress in Individuals with Autism Spectrum Disorders
}

Kunio Yui

Research Institute of Pervasive Developmental Disorders, Ashiya University Graduate School of Education, Rokurokusocho 13-22, 659-8511, Ashiya, Japan

"Corresponding author: Kunio Yui. Research Institute of Pervasive Developmental Disorders, Ashiya University Graduate School of Education, Rokurokusocho 13-22, 659-8511, Ashiya, Japan; Tel: 0797-38-6725; E-mail: yui16@bell.ocn.ne.jp

Rec date: May 05, 2014; Acc date: May 06, 2014; Pub date: May 10, 2014

Copyright: @2014 kunio yui. This is an open-access article distributed under the terms of the Creative Commons Attribution License, which permits unrestricted use, distribution, and reproduction in any medium, provided the original author and source are credited.

\section{Editorial}

The common characteristics and patterns of individuals with Autism Spectrum Disorders (ASD) include the need for consistency, rituals, predictability and problem solving [1]. The constant changing nature of unfamiliar social interactions that require spontaneous intuitive adjustment may exacerbate socially related anxiety for these individuals with ASD [1]. Accumulating evidence indicates that individuals with ASD were easily suffered from anxiety symptoms in stressful situations [2-4]. For example, salivary cortisol levels were significantly increased in response to an unfamiliar peer compared to a familiar peer in thirty-three children aged 6-13 years [1]. The peer interaction paradigm resulted in significantly higher levels of salivary cortisol in 21 children with ASD aged 8 to 12 years compared to normal controls, suggesting that the ASD children easily activate hypothalamic-pituitary-adrenal (HPA) responses in social situations [3]. Twenty-seven male children with ASD aged 8 to 12 years maintained an elevated cortisol level in response to standardized social-evaluative performance task compared to children with agematched 32 typical developments [4].

Children with ASD spent approximately $62 \%$ more time watching television and playing video games than in all non-screen activities combined. Compared with TD siblings, children with ASD spent more hours per day playing video games ( 2.4 vs. 1.6 for boys, and 1.8 vs. 0.8 for girls) [5]. Among 860 students with ASD aged 13-16 years, the majority of youths with ASD (64.2\%) spent most of their free time using non-social media (television, video games) [6]. Videogame effects are complex and would be better understood as multiple dimensions rather than a simplistic "good-bad" dichotomy [7]. Actually, video game play did not increase up-regulation of salivary serum [8] or salivary [9] cortisol levels. Moreover, casual video game decreased physiological stress responses [10]. Thus, video game play can decrease physiological stress responses.

It is therefore possible that video game play may distract stress response in individuals with ASD. The author examined the relation of between video game play and plasma cortisol response to three types of stress situation such as interruption of video game play and interpersonal communication with unfamiliar adults, and asked questions on the most unpleasant in 10 individuals with ASD compared to 7 healthy normal controls.

Full details of study procedures were described in our previous report [11]. During video game for 40 minutes, a structured interview consisting of the declarative memory recall was carried out. Before the start of the interviews, each participant played a TV-based videogame as the default context. Two serial contexts followed in which participants were exposed to different social and emotional stimuli for 7 minutes each (a total of 14 minutes) during which time all

individuals were ceased video game play. Two types of the stimulators such as an unfamiliar female and an unfamiliar male made a structured interview on most unpleasant daily events in their personal relationship to their peers or teachers in their school, respectively. Blood specimens for plasma cortisol determination were conducted at the time of 28 days before and again 5 minutes after the interviews.

Noteworthy is the fact that there were no significant differences in plasma cortisol levels between the 10 children with ASD and the 7 normal controls both at 28 days before the interviews, and at 5 minutes after the interviews.

In respect to the effects of memory retrieval on cortisol response, an inverted U-shaped dose-response relationship between salivary cortisol levels and recall performance was observed with moderate elevation of salivary cortisol resulting in the best recall performance [12]. Moreover, memory retrieval testing after the learning session was strongly associated with urine cortisol secretion [13] or salivary cortisol response [14]. Therefore, memory retrieval of the unpleasant daily events may have been induced increased plasma cortisol response.

In this study, there were different types of stressful situations. These were as follows: 1) interaction with two unfamiliar adults during video game play; 2) memory retrieval on most unpleasant daily events; 3 ) disruption of videogame play by asked question. However, plasma cortisol levels in the 10 children with ASD were not significantly increased in the above described test setting. As described above, video game did not induce in change serum [8] or salivary [9] cortisol levels. Interestingly, video game play changed autonomic nervous system relaxation or decreased physiological stress responses as indicated by electroencephalographic changes and hears rate variability [10]. Moreover, the video game successfully distracted stress of patients during the dental procedure [15]. Drawing these strands together, the video game play may distract plasma cortisol response to stressful setting.

Although detailed neurobiological mechanisms associated with flat responses of cortisol profile in the 10 children with ASD are not clearly understand, there were two factors may be considered as follows: stressful situation used in thus study was not so strong to induce any changes in plasma cortisol levels; 2) considering previously reported findings that younger children who showed willing to approach to others did not increase cortisol response [16], the 10 individuals with ASD in this study may be willing to approach unfamiliar adults, and thus showed no changes of plasma cortisol response.

Collectively, it is plausible that video game play may be able to distract cortisol response to psychosocial stress. 
Citation: Yui K (2014) Video Game Play May Attenuate Cortisol Response to Psychosocial Stress in Individuals with Autism Spectrum Disorders. J Socialomics 3: e124. doi:10.4172/2167-0358.1000e124

Page 2 of 2

\section{References}

1. Lopata C, Volker MA, Putmam SK, Thomeer ML, Nida RE (2008) Effect of social familiarity on salivary cortisol and self-reports of social anxiety and stress in children with high functioning autism spectrum disorders. J Autism Dev Disord 38: 1866-1877.

2. Simon DM, Corbett BA (2013) Examining associations between anxiety and cortisol in high functioning male children with autism. J Neurodev Disord 5: 32.

3. Corbett BA, Schupp CW, Simon D, Ryan N, Mendoza S (2010) Elevated cortisol during play is associated with age and social engagement in children with autism. Mol Autism 27: 13.

4. Corbett BA, Schupp CW, Lanni KE (2012) Comparing biobehavioral profiles across two social stress paradigms in children with and without autism spectrum disorders. Mol Autism 3: 13.

5. Mazurek MO, Wenstrup C (2013) Television, video game and social media use among children with ASD and typically developing siblings. J Autism Dev Disord 43: 1258-1271.

6. Mazurek MO, Shattuck PT, Wagner M, Cooper BP (2012) Prevalence and correlates of screen-based media use among youths with autism spectrum disorders. J Autism Dev Disord 42: 1757-1767.

7. Prot S, McDonald KA, Anderson CA, Gentile DA (2012) Video games: good, bad, or other? Pediatr Clin North Am 59: 647-658.

8. Chaput JP, Visby T, Nyby S, Klingenberg L, Gregersen NT, et al. (2011) Video game playing increases food intake in adolescents: a randomized crossover study. Am J Clin Nutr 93: 1196-1203.
9. Ivarsson M, Anderson M, Åkerstedt T, Frank Lindblad F (2009) Playing a violent television game does not affect saliva cortisol. Acta Pediatrica 98: 1049-1056.

10. Russoniello CV, O’Brien K, Parks JM (2009) EEG, HRV and Psychological correlates while Playing Bejeweled II: a randomized controlled study. Stud Health Technol Inform 144: 189-192.

11. Yui K, Ohnishi M (2013) Plasma cortisol response to askedquestions on recent events during videogame play in individuals with autism spectrum disorders. Am J Clin Med Res 1: 65-70.

12. Schilling TM, Kölsch M, Larra MF, Zech CM, Blumenthal TD, et al. (2013) For whom the bell (curve) tolls: Cortisol rapidly affects memory retrieval by an inverted U-shaped dose-response relationship. Psychoneuroendocrinology 38: 1565-1572.

13. Goerke M, Cohrs S, Rodenbeck A, Grittner U, Sommer W, et al. (2013) Declarative memory consolidation during the first night in a sleep lab: the role of REM sleep and cortisol. Neuroendocrinology 38: 1102-1111.

14. Ackermann S, Hartmann F, Papassotiropoulos A, de Quervain DJ, Rasch B (2013) Associations between Basal Cortisol Levels and Memory Retrieval in Healthy Young Individuals. J Cogn Neurosci 25: 1896-1907.

15. Seyrek SK, Corah NL, Pace LF (1984) Comparison of three distraction techniques in reducing stress in dental patients. J Am Dent Assoc 108: 327-329.

16. Schupp CW, Simon D, Corbett BA (2013) Cortisol responsivity differences in children with autism spectrum disorders during free and cooperative play. J Autism Dev Disord 43: 2405-2417. 